\title{
Becoming:
}

\section{Identity and Spirituality}

\author{
Rowena A. Pecchenino \\ Department of Economics, Finance \& Accounting \\ National University of Ireland, Maynooth \\ Maynooth \\ Co. Kildare \\ Ireland \\ Rowena.Pecchenino@nuim.ie \\ +3531 7083751 (phone) \\ +35317083934 (fax)
}

July 2008

I would like to thank the seminar participant at the National University of Ireland Maynooth, the Geary Institute, University College Dublin, and the conference participants at the 2008 Irish Economic Association Conference. I would especially like to thank Peter Carney and Ken McKenzie for their comments. 


\title{
Becoming: Identity and Spirituality
}

\begin{abstract}
An individual's identity answers the questions of who, what, where, and why the individual is. An overall identity is made up of multiple constituent identities. These identities may not be fixed over the life course, but may change as a result of conscious choices as well as serendipity or calamity - life transforming events which cannot be anticipated, which remove what had been the certainties and norms of life, and which can leave the individual disconnected from what had been her past and from her hoped for future. In this paper we develop a two-period behavioral model of an individual whose personal identity is an amalgam of $N$ identities, one or more of which may be spiritual in nature. Some identities are actualized at a point in time and some remain latent. We model how individuals allocate resources among current and hoped for future identities, and how these resource allocation decisions and identity actualizations are affected by the interaction of choices and unanticipated external events. We argue why a spiritual identity may be actualized, how it interacts with other identities, and why, in giving context to an individual's life, it enables her to define and to strive toward her overall identity - to become.
\end{abstract}

JEL Classification: Z12, Z13

Keywords: Identity, Spirituality 


\section{Introduction}

An individual's identity answers the questions of who, what, where, and why the individual is. An overall identity is made up of multiple constituent identities. These identities may not be fixed over the life course, but may change as a result of conscious choices, serendipity or calamity. Serendipity and calamity, life transforming events which cannot be anticipated and which remove what had been the certainties and norms of life, the personal and social anchors, can leave the individual disconnected from what had been her past and from her hoped for future. To move from this anomic state to a new set of identities, the individual must develop new certainties or rediscover old ones that had been lost. This unplanned and un-chosen transformation of self may cause an individual to discern within her an always present but perhaps latent spiritual identity through which she can gain "a clearer life purpose" (Mayo Clinic, 2006) or "integrate [her] life in terms not of isolation and selfabsorption but of self-transcendence toward the ultimate value [she] perceives” (Schneiders, 1986, p.266). The process of integrating her life, of establishing a new overall identity, the amalgam of her identities both past and present, necessitates that she reallocate resources emotional, psychological and physical - away from what she had initially planned to these new or heightened aspects of her identity.

The identities which together define the individual and to which she aspires are archetypes, where the archetype, the ideal, the model, is perceived by the individual, and could be defined by societal beliefs, the teachings of a mentor, or one's own personal perception however come by. To the extent that an identity is a social identity, it is what one believes society believes that defines the identity archetype. To the extent that an identity is personal and private rather than social, the teachings of a mentor or one's personally formed ideal may define the archetype. Since individuals have multiple, interdependent identities, the effort put forth, both past and present, to achieve one identity may spill over positively or negatively onto the attainment of other identities. Spirituality, or a spiritual identity, is variously defined, "but at 
its core spirituality helps to give our lives context” (Mayo Clinic, 2006). As such, a spiritual identity provides a means to integrate one’s other identities both within oneself and with society. It makes sense of and unifies the various aspects of one's life.

To better understand how the individual makes her choices for the present and her plans for the future, and to understand how these decisions change as a result of the interaction of her actions and external events, we extend Jeitschko, O’Connell and Pecchenino’s (2008) simple static behavioral model of an individual whose personal identity is an amalgam of $N$ identities, one or more of which may be spiritual in nature. In our two-period extension some identities are actualized at a point in time and some remain latent. Specifically we model how individuals allocate resources among identities, those actualized today and those hoped to be actualized tomorrow, and how these resource allocation decisions are affected by the interaction of individual investments specific to an identity or generally applied to many identities and external events that effect unanticipated changes to the individuals' personal, social and economic environments. We argue why a spiritual identity may be actualized, how it interacts with other identities, and why, in giving context to an individual's life, it enables her to define and strive toward her overall identity - to become.

\section{Background/Foundation in Literature}

The standard representation of an individual in economics is a single preference ordering, a single identity that is fixed through time. Individuals pursue their own self-interest. Sen (1977) has challenged this as being too simplistic. First, he argues (Sen 1985, 2002) that individual decision making cannot be characterized by optimizing one’s self interest. Individuals have goals and make choices that are inconsistent with self interest or personal gain no matter how broadly or narrowly defined. Rather, individuals are committed to particular social behaviors either to obtain a goal, such as social justice, which may bring them to harm in the hope of benefiting society, or to maintain the social structure within 
which they live by holding to societal behavioral norms (Sen 1997). Second, individuals do not have a single preference ordering but, rather, have multiple preference orderings, which could be interpreted as multiple identities, over a given set of choices. The individual then must have a preference ordering over the multiple orderings, but this ordering may not be complete. This incomplete ordering can lead to individuals exhibiting time inconsistent behaviors, as which ordering takes precedence at a moment in time may depend on any number of exogenous or endogenous factors.

Akerlof and Kranton (2000, 2005) introduced the concept of identity and preferences based on achieving an assigned social identity rather than simply maximizing one's narrow selfinterest to mainstream economic discourse. While they maintain the concept of a single preference ordering and do not consider selfless, socially committed behaviors, they broaden the analysis to include the individual's social setting, how he is placed therein (by assignment rather than choice), and how he behaves to both be what society expects him to be and to minimize the cognitive dissonance of defying social expectations. Their models are closely related to models of socially referenced preferences, which also assume a single preference ordering and self-interested behavior, such as Veblen (1934), Duesenberry (1949), Easterlin (1974), Frank (1985), and Clark and Oswald (1998), among others. In Akerlof and Kranton’s analyses, in contrast to the socially referenced preference literature, individuals try to obtain an ideal identity rather than assessing their happiness relative to others in their chosen reference group.

Kirman and Teschl (2004, 2006), Teschl (2006) and Horst, Kirman and Teschl (2006) acknowledge the strengths and weaknesses of standard economic theory and its extensions while taking seriously Sen's criticisms to better model identity and choice. Specifically, they agree that the standard representation of an economic agent is in terms of a given preference ordering. These preferences are fixed over time and, together with the specific constraints the agent faces, the agent attempts to maximize his utility. This gives a simple picture of the 
agent's identity at each moment in time by describing what the agent is. Introducing preferences for one's social identity expands rather than changes this simple view of a global and unchanging preference ordering, by adding to the description of the economic agent's identity more information as to where the agent is situated within a social space. Individuals change by choosing to belong to social groups in order to become who they want to be and to realize their, not necessarily fixed, self-image. By choosing their social groups, people are consciously changing what and where they are right now, thus changing their preference ordering, to become who they would like to be in the future. The social group is a mechanism for people to acquire those characteristics they would like to have. However, people will not necessarily remain tied to their choices of social groups because these groups may themselves change over time. Ultimately, of course, who they want to be might also change as a consequence of their search for identity. But, this conscious and continuous change leads to incomplete preference orderings, and thus what will appear to be time inconsistent choices.

Kirman and his colleagues model how an individual defines himself by choosing to change through time. That individual remains identifiable as a unique individual across change, as required by Davis’s (2006) conception of the individual. This is in contrast to Parfitt (1971) who characterizes the individual as a sequence of selves. Bazin and Ballet (2006) can be considered a formalization of Parfitt's framework. They characterize the individual as having multiple selves simultaneously, like multiple but independent identities. Their model also suggests that the individual's preference ordering will not be complete.

In our model, individuals have a single self which is comprised of multiple, interdependent identities. The individual's preference ordering is defined over these identities. At a point in time only some identities are actualized, and thus known to the individual, while others remain latent, and thus unknown to the individual. Individuals devote resources today to obtain their (actualized) identity goals today, that is, to move them closer to the identity archetype they perceive, and invest to obtain both their expected and hoped for identity 
archetypes tomorrow. This can be thought of as investing in identity specific or general identity capital. Thus, the agent balances current and hoped for future identities to achieve her overall identity rather than one identity being dominant in one situation and another being dominant in another situation. However, unforeseen and unanticipated events, either serendipitous or calamitous, which interact with the individual's current identities and investments in future identities can lead currently actualized identities to become latent in the future and actualizations of hoped, planned, and invested in identities not to occur. Instead, identities now latent and not hoped or planned for or invested in may be actualized. When unanticipated events lead to a substantial redirection of an individual's life, a spiritual identity may be actualized or if already actualized may become heightened. This identity provides a mechanism by which the individual can integrate her identities both past and present, make sense of the forces that have changed her life plans, and thereby come to an understanding of not only what, where, and who she is, but ultimately why she is.

\section{The Model}

In our model agents invest in identities to achieve a desired self over their two-period lifetimes. ${ }^{1}$ The individual agent has a single preference ordering defined over $N$ distinct but interdependent identities in both the first and second periods of her life. Some identities may be latent at each point in time, while others may be actualized. The agent recognizes only the preference ordering over actualized identities. The agent invests effort today and plans to invest effort tomorrow in identities actualized today which are believed to remain constituent parts of her identity tomorrow. These identities define what and where she is today. She also invests today in behaviors that prepare her to take on additional hoped for (not yet actualized) identities to achieve what she now perceives as her lifetime personal ideal and which define who she wants to become. Currently actualized identities can be in harmony or conflict in

\footnotetext{
${ }^{1}$ Consistent with Sen $(1985,1997,2002)$, one's self may be defined by attaining a social goal or by social behaviors which may require the typical economic self to be sacrificed. But, inconsistent with Sen, the agent has a single preference ordering.
} 
that effort dedicated to one identity can move the agent closer to or farther away from another identity goal. Hoped for identities may neither be actualized tomorrow nor, indeed, be a component of her preference ordering. Individuals, no matter how much they try to be otherwise, are constrained by who they are, their underlying preferences, even if who they are is not precisely known to them.

Let

$$
U\left(A^{n 1}\left(i^{n 1}-i^{n 1^{*}}\right), \ldots, A^{N 1}\left(i^{N 1}-i^{N 1^{*}}\right)\right)+V\left(A^{n 2}\left(i^{n 2}-i^{n 2^{*}}\right), \ldots, A^{N 2}\left(i^{N 2}-i^{N 2^{*}}\right)\right)
$$

represent an individual's preference ordering over identities which defines her overall or composite identity. $A^{n t}=1$ if identity $n$ is actualized in period $t, 0$ otherwise, $n=1, \ldots, N, t=$ 1, 2. Utility/Overall Identity is a function of each of her $n=1, \ldots, N$ time-specific identities relative to their ideals, $i^{n t}-i^{n t^{*}}$, for all $n, t=1$, 2. Assume $\mathrm{U}_{n}\left(\ldots, A^{n l}\left(i^{n 1}-i^{n 1^{*}}\right), \ldots\right)>0(<0)$ for $i^{n l}-i^{n 1^{*}}<0(>0)$, and for all $n=1, \ldots, \mathrm{N}$, and that $U_{n n} \leq 0$ for all $n=1, \ldots, \mathrm{N}$, for $A^{n l}=1$. Similarly, assume $\mathrm{V}_{n}\left(\ldots, A^{n 2}\left(i^{n 2}-i^{n 2^{*}}\right), \ldots\right)>0(<0)$ for $i^{n 2}-i^{n^{*}}<0(>0)$, and for all $n=1, \ldots$ ,N, and that $V_{n n} \leq 0$ for all $n=1, \ldots, \mathrm{N}$, for $A^{n 2}=1$. The sign of $U_{n m} n \neq m\left(V_{n m}, n \neq m\right)$ is positive if his $n$ and $m$ identities are complements, negative if they are substitutes, and zero if they are independent.

Assume that an individual's identities and the effort (psychological, emotional, spiritual, and physical resources expended) required to attain them are related as follows

$$
i^{n t}-i^{n t^{*}}=\hat{e}^{n t}-e^{n t^{*}}+\varepsilon^{n}\left(e^{t-1}\right)
$$

where

$$
\hat{e}^{n t}=e^{n t}+\sum_{m \neq n} \beta^{m n t} e^{m t}, \quad m, n=1, \ldots, N, t=1,2
$$

and 


$$
\hat{e}^{n 0}=0
$$

where $\hat{e}^{n t}$ is the effort the individual puts into her $n$th identity in period $t$, which is the sum of her effort dedicated to her $n$th identity, $e^{n t}$, and any spillover from effort dedicated to her other identities, $\beta^{n n t} e^{m t}$, for all $m, t=1,2$, where $\beta^{n n t}<1$. $e^{n t^{*}}$ represents the individual's belief of the effort required to attain the ideal identity. These personal beliefs can depend on context, the personal, familial, social, intellectual and spiritual environment in which the individual finds herself, and can be social or personal constructs depending on the identity. Intertemporal spillovers, $\varepsilon^{n}\left(e^{t-1}\right)$, depend on last period's effort that was either directly intended to achieve identity $n$ in period 2 or via an intertemporal spillover from actions taken to achieve period 1 goals on initial distance from period 2 goals.

Assume, further, that the individual's initial identity actualizations depend on environmental, familial, spiritual and social factors, $\theta^{n l}$. These initial identity actualizations depend on how the individual's underlying preferences interact with her environment, and are thus similar to identity assignments in Akerlof and Kranton (2000). The actualizations of an individual's future identities depend on the identities actualized in period 1 , which allows for path dependence, and can be affected by her investments in future identity capital, $e^{n l, 2}$, which allows the agent to influence her lifetime identity composition. But, her actions dedicated to achieving her current identity goals, her social setting, her underlying preferences as well as factors beyond her control, unanticipated and unable to be anticipated in period $1, \theta^{n 2}$, also affect future identity actualizations. Thus,

$$
\begin{aligned}
& A^{n 1}=A^{n 1}\left(\theta^{n 1}\right) \\
& A^{n 2}=A^{n 2}\left(e^{n 1,2} ; \hat{e}^{n 1}, \theta^{n 2} ; A^{11}, \ldots, A^{N 1}\right), n=1, \ldots, N
\end{aligned}
$$

where, in general, if $A^{n 1}=1$, then the agent will believe that $A^{n 2}=1$ : initial identities are believed to persist throughout life. 
The individual, then, given her initial identity actualizations, must divide her total resources in period 1

$$
e^{1}=\sum_{n}\left(e^{n 1}+e^{n 1,2}\right)
$$

and plan to divide her total resources in period 2

$$
e^{2}=\sum_{n} e^{n 2}
$$

to try to achieve her overall identity goals today and her aspirations for the future. These decisions take spillovers, both positive and negative, from one identity to another and the complementarity or substitutability of identities into account.

To imagine the individual's decision problem more precisely, assume that in period 1 identities 1 and 2 are actualized, and are thus believed to remain actualized for the rest of her life. Assume that she hopes that another identity, call it identity 3, will be actualized in period 2, and makes investments specific to that identity to prepare herself to take on this additional identity in the future. Notice, this identity may not be a constituent identity in her preference ordering, but she believes it to be and wants to induce its future actualization. Thus, her decision problem is to allocate her resources to meet her identity goals today and to situate her to achieve her hopes and goals for tomorrow.

Substituting equations (2) - (5) into (1) yields her objective function

$$
\begin{aligned}
& U\left(e^{11}+\beta^{211} e^{21}-e^{11 *}, e^{21}+\beta^{121} e^{11}-e^{21} *\right)+ \\
& \mathrm{H}_{1} V\left(e^{12}+\beta^{212} e^{22}+\beta^{312} e^{32}-e^{12} *+\varepsilon^{1}\left(e^{1}\right),\right. \\
& \quad e^{22}+\beta^{122} e^{12}+\beta^{322} e^{32}-e^{22} *+\varepsilon^{2}\left(e^{1}\right), \\
& A^{32}\left(e^{1}-e^{11}-e^{21} ; \theta^{32} ; A^{11}, A^{21}\right)\left(e^{32}+\beta^{132} e^{12}+\beta^{232} e^{22}-e^{32} * \varepsilon^{3}\left(e^{1}\right)\right)
\end{aligned}
$$

where $\mathrm{H}_{1}$ represent her hopes as of period 1 , where she assumes that $A^{11}=A^{21}=A^{12}=A^{22}=1$ and $A^{n 2}\left(e^{n 12}, e^{n 1}, \theta^{n 2} ; A^{11}, A^{21}\right)=1$ if $e^{n 12}>0,0$ otherwise, and where $e^{2}=e^{12}+e^{22}+e^{32}$. That 
is, she plans for what is, what she thinks will be and what she hopes will be. Hopes for the future, unlike expectations, do not necessarily rely on objective evidence or a probabilistic calculation of what is likely to occur. They are more another expression of current tastes, of innate characteristics, of beliefs that define what she hopes to be her lifetime identity. It may be, however, that the relationship between her current and future identities that she imputes to herself in her hopes for her future will not prove to be accurate characterizations of her actual underlying preferences, and so the values of the spillover effects, the $\beta$ 's and $\varepsilon$ 's, the identity goals, $e^{*}$, and the characteristics of the $V()$ function, may be far from accurate. Thus, even if her hopes are realized in that her hoped for identity is actualized, the reality may be quite different than the dream.

She chooses her current resource allocation and her planned resource allocation for her hoped for future. These choices are made and current actions are taken in period 1 . These actions move her closer to her period 1 identity archetypes and prepare her for her hoped for future. Then, at the onset of period two the $\theta^{n 2}$ are realized, which in conjunction with her first period identity actualizations and her identity investments determine which second period identities will be actualized. At this juncture the relationship among her past and future identities is revealed. To the extent these were not what she had hoped for or imagined if hoped for, the individual must come to terms with and discern what now is. To the extent that the realizations of the $\theta^{n 2}$ can be considered life-altering, thereby negating some or all previous and hoped for identities, an identity which helps make sense of her life already lived and her life yet to come, that is a spiritual identity, may be actualized, or strengthened if already actualized. This identity provides the individual with a means to put her life into context, to understand why.

To make this concrete, consider the following cases. In the first, the hoped for future comes to pass (identities 1, 2 and 3 are actualized in period 2) leading to a high intertemporal spillover $\left(\varepsilon^{3}\left(e^{1}\right)\right.$ large as a result of her identity specific investment $\left.e^{31.2}\right)$, thus placing the 
individual 'close' to her identity goals. In the second, identities 1 and 2 are again actualized, and another identity, perhaps but not necessarily similar to the hoped for identity 3, call it identity 4, is actualized. This leads to a smaller intertemporal spillover from her identity 3 specific investments, and places the individual at a greater distance from her identity goals. In the third, all period 1 identities are lost and a new set of identities replaces them. Call these identities 5, 6 and 7. The extent of intertemporal spillovers depends on how general her investments in period 1 goal achievement and her investments in her hoped for period 2 identity were. Indeed, these spillovers could be negative thereby putting her initially farther away from her identity goals than if she had no past. Instead, these spillovers could be positive, the individual experiencing an epiphany which brings clarity to both past and future. In all these cases the individual must allocate her effort, her resources, given her actualized identities taking her past as given.

Case 1:

$$
\begin{aligned}
V\left(e^{12}+\beta^{212} e^{22}+\beta^{312} e^{32}-e^{12} *+\varepsilon^{1}\left(e^{1}\right),\right. \\
e^{22}+\beta^{122} e^{12}+\beta^{322} e^{32}-e^{22} *+\varepsilon^{2}\left(e^{1}\right), \\
\left.e^{32}+\beta^{132} e^{12}+\beta^{232} e^{22}-e^{32} *+\varepsilon^{3}\left(e^{1}\right)\right)
\end{aligned}
$$

Case 2:

$$
\begin{aligned}
V\left(e^{12}+\beta^{212} e^{22}+\beta^{412} e^{42}-e^{12} *+\varepsilon^{1}\left(e^{1}\right),\right. \\
e^{22}+\beta^{122} e^{12}+\beta^{422} e^{42}-e^{22} *+\varepsilon^{2}\left(e^{1}\right), \\
\left.e^{42}+\beta^{142} e^{12}+\beta^{242} e^{22}-e^{42} *+\varepsilon^{4}\left(e^{1}\right)\right)
\end{aligned}
$$

where $\varepsilon^{3}\left(e^{1}\right)>\varepsilon^{4}\left(e^{1}\right)$.

Case 3:

$$
\begin{aligned}
V\left(e^{52}+\beta^{652} e^{62}+\beta^{752} e^{72}-e^{52} *+\varepsilon^{5}\left(e^{1}\right),\right. \\
e^{62}+\beta^{562} e^{62}+\beta^{762} e^{72}-e^{62} *+\varepsilon^{6}\left(e^{1}\right), \\
\left.e^{72}+\beta^{572} e^{52}+\beta^{672} e^{62}-e^{72 *}+\varepsilon^{7}\left(e^{1}\right)\right)
\end{aligned}
$$


where any of the $\varepsilon^{n}\left(e^{1}\right), n=5,6,7$, could be either positive or negative. It is situations such as Case 3, where the external events can be either serendipitous or calamitous, bringing joy, an epiphany or dislocation and challenge, where a spiritual identity can be expected to be actualized or heightened. If a spiritual identity is actualized, call it identity 7, because it provides a means to integrate one's life, and thus one's currently and previously actualized identities, it would have the following characteristics. First, $\beta^{752}$ and $\beta^{762}$ would be large and positive, as effort put into the individual's spiritual identity will have positive spillovers onto her other identities. Second, identity 7 will be complementary to identities 5 and 6 . Third, since the spiritual identity helps her put her life into context, $\varepsilon^{5}\left(e^{1}\right), \varepsilon^{6}\left(e^{1}\right)$, and $\varepsilon^{7}\left(e^{1}\right)$ will be positive or small if negative: understanding her past enables the individual to use it productively to build her future.

Observation 1: Appearance of time inconsistent behavior.

Because an individual's preferences are revealed as a result of life experiences, her behavior, how she allocates her period 2 effort, $e^{2}$, may appear to be time inconsistent. Yet, this 'inconsistent' behavior is actually consistent with and reflects her growing knowledge of who she is which depends on where she has come from (the identities actualized in period 1), what she has experienced (her period 1 effort allocation and the resulting strengthening of her identities as well as her investments in her hoped for identities), and what has befallen her (the $\theta^{\mathrm{n} 2} \mathrm{~s}$ ). Her initial plans for and investments in her future affect how she experiences that future via the interaction of events and her actions. However, to the extent that the future from the perspective of period 1 is unknown and unknowable and to the extent that one's selfknowledge is incomplete, even the best laid plans may be modified if not discarded.

For Case 1 plans would be likely to appear to be time consistent while for Case 3 they would appear time inconsistent. Additionally, the individual in Case 3 would appear to be a different individual in period 2 than in period 1, suggesting a Parfitt-like (1971) sequence of 
individuals where the period 2 individual is the beneficiary of the period 1 individual's history but is a distinct being. Here, however, the period 1 individual and period 2 individual are indeed the same person, bound by a single underlying preference ordering over identities. Thus Davis’s (2006) criterion for individuation will be met suggesting that designating the individual's behavior as time inconsistent fails to recognize the forces which determine an individual's resource allocation decisions and plans.

Observation 2: General vs specific identity capital and from where you begin again.

If an individual is very future focused, and invests heavily in period 1 in identity 3 specific capital so as to prepare herself to take on identity 3 in the future, and if identity 3 is not actualized (or perhaps not even in her preference ordering) but an identity 4 is, not only have her investments failed to pay off as expected, she may find herself with little to build her new life upon. That is, the spillovers from her past actions can move her away from rather than closer to her newly actualized identity goals. Specifically, her period 1 effort choices and their anticipated intertemporal spillovers, $\varepsilon^{3}\left(e^{1}\right)$, and her plans for period 2 effort made in period 1 and their anticipated intratemporal spillovers, $\left(e^{32}+\beta^{132} e^{12}+\beta^{232} e^{22}\right)$, which were all intended to get her close to what she believed would be her identity 3 goal, $e^{32} *$, her hoped for additional identity from the perspective of period 1, can place her farther away from the actualized identity 4 goal $e^{42} *$ she perceives, thereby making the transition to this new identity more challenging and personal fulfillment (achieving or getting sufficiently close to one’s identity goals) less likely. Had her hopes for the future been less well defined, so that she invested in general identity capital, in behaviors and skills important to many identities, then the transition to the new identity would be less traumatic since the distance from her new identity goal would be less. The individual who invests in general rather than specific skills or behaviors is more adaptable when the hoped for future does not come to pass. However should it, she is less well prepared than those who, in retrospect, appear prescient. This prescience could be a function of environmental stability in which the past generally provides 
an excellent prediction of the future, perhaps in the case of a traditional society, or of risktaking behavior when the future is unknown and unknowable but when one's desire to will a specific future into existence are strong: $e^{31,2}$ dominates most adverse realizations of $\theta^{32}$ and strengthens positive realizations.

Observation 3: Spirituality- the identity that unifies all individual identities into a consistent whole.

When an individual's plans do go awry, as in Case 3, so that what one thought would continue to be (identities 1 and 2) and what one hoped for would come to be (identity 3) do not (consider the wife and mother who anticipates grand-motherhood who loses her husband and adult child in an automobile accident, or a member of a nomadic tribe who expects to live out his life much as his ancestors did who, rather, as a result of a war becomes a refugee in a first-world country), another set of identities must be actualized to fill the void. Since the past cannot be erased, something in the set of new identities must make sense of the past and the realized present, combining the two into a coherent whole. Because "spirituality helps to give our lives context” (Mayo Clinic, 2006), a spiritual identity providing a way to do so may be actualized in response to life-altering events. Actualization of a spiritual identity, on its own, does not give life context, but it does provide a mechanism or a framework by which this goal can be achieved. Further, this context for one's life suggests that it and other identities will be complementary and effort allocated to one’s spiritual identity will positively spill over onto other identities since both suggest a lowered cost of being gained by working with rather than against what is, and that the past made sense of is not a drag on the future. These are, precisely, the effects mentioned above. But the ability to work with rather than against may be hard won especially if the individual had invested heavily in identity specific capital not suited to her new reality. Thus, significant effort could be required before any benefits, either direct or indirect, can be achieved. In such a case, should a strong substitute identity also be actualized which requires less effort to achieve (perhaps the identity of victim in the example 
of the bereaved wife and mother noted above where the individual refuses to try to make sense of her past but rather defines herself by her losses), it rather than the spiritual identity may absorb the bulk of the individual's resources. ${ }^{2}$ However, if the returns to achieving the overall identity goal, the amalgam of all her identity goals, are adequately high at feasible levels of effort, even if at low levels of effort (initially) decreasing returns are experienced, the agent still may choose what appears to be to observers and often feels like to the individual herself the more difficult yet ultimately more fulfilling path. Notice, part of the challenge of attaining her new individual and overall identities is found in her beliefs concerning the effort required to attain the ideal newly actualized identities. Since these beliefs depend on context, the calamity or epiphany that changed the direction of her life may also affect her beliefs and thus her identity goals.

Spirituality also could feature in Case 2 . In this case, suppose identity 1 is the spiritual identity and as a result of having this identity the loss from the hoped for identity 3 having not been actualized is lessened. Thus, $\varepsilon^{4}\left(e^{1}\right)$ would be positive and larger than without the context the spiritual identity provides, and the benefits of complementary identities and positive spillovers from effort invested in identity 1 in period 2 on identity 4 would ease the individual's transition to her new overall identity.

Observation 4: Regret and disappointment: Evaluating past behavior from the perspective of the present.

When events transpire against an individual so that hopes are dashed, or when one's perspective is changed as a result of the actualization of a new identity, there is the possibility that the individual may regret past choices. This regret does not suggest any decisions that had been taken would not again be taken given the same information, the same experience,

\footnotetext{
${ }^{2}$ In the static one period setting that characterizes decisions taken in period 2, if an agent has two identities which are strong substitutes and/or if spillovers across identities are negative, then she may choose to allocate all her resources to one of the two identities. See Jeitschko, et al, 2008.
} 
and the same identity actualizations, but that from the perspective of the present reviewing the past, were the individual to have known then what she knows now about herself, she would have acted differently and thus regrets her actions. This situation is distinct from the regret described by O’Donoghue and Rabin (2001) when an individual knows her lifetime utility function but has self-control problems. Rather it is more like Gershlager's (2007) analysis of Smith's 'poor man's son' in which deepening personal knowledge and change of identity may cause an individual to, in taking stock of her life, regret her past actions. An individual may also suffer from disappointment. Since the past cannot be erased, neither can the hoped for future. That the desired future was not obtained and ultimately proved unattainable reduces the benefit of what is by the memory of what may have been $\left(\varepsilon\left(e^{1}\right)\right.$ large and negative).

\section{Conclusion - Spirituality and Identity}

Each person, balancing and integrating many identities, which may change over the life course as a result of actions taken as well as unforeseen and unanticipated serendipitous or calamitous events, struggles to discover why and to become who she is. This process, a life lived, is difficult. Navigating it successfully requires the ability to make sense of both internal and external forces, place one’s life (past, hoped for future, and realized future) in context, and to build on what one has rather than what one has not. What spirituality or a spiritual identity gives to identity theory is a means for an individual's diverse identities, her choices and plans, the predictable and unpredictable events, and the internal and external forces that determine the life course to be integrated into a sense of self, the what and where as well as the who and why defining an overall identity. It provides a means to become. 


\section{References}

Akerlof, G.A., Kranton, R.E., 2000. Economics and Identity. Quarterly Journal of Economics 115, 715-753.

Akerlof, G. A., and Kranton, R. E., 2005. .Identity and the Economics of Organizations. Journal of Economic Perspectives. 19(1), 9-32.

Bazin, D., Ballet, J., 2006. A basic model for multiple self. The Journal of Socio-Economics 35, 1050-1060.

Clark, A.E., Oswald, A.J., 1998. Comparison-concave Utility and Following Behaviour in Social and Economic Settings. Journal of Public Economics 70, 133-155.

Davis, John B., 2006. Social identity strategies in recent economics. Journal of Economic Methodology 13:3, $371-390$.

Duesenberry, J., 1949, Income, Saving, and the Theory of Consumer Behavior. Cambridge, MA: Harvard University Press.

Easterlin, R.A., 1974. Does Economic Growth Improve the Human Lot? Nations and Households in Economic Growth. In: David, P.A., Reder, M.W. (Eds.). Essays in Honour of Moses Abramovitz. New York: Academic Press, Inc., 89-125.

Frank, R., 1985, The Demand for Unobservable and Other Nonpositional Goods. American Economic Review 75, 101-116. 
Gerschlager, C., 2008, Foolishness and Identity: Amartya Sen and Adam Smith. DULBEA Working Paper No. 08-03RS.

Horst, U., Kirman, A., Teschl, M., 2006. Changing Identity: The Emergence of Social Groups. GREQAM Working Paper 2006-51.

Jeitschko, T., O’Connell, S., Pecchenino, R., 2008. Identity, Collective Beliefs, and the Allocation of Resources. Economic and Social Review 39(1), 39-54.

Kirman, A., Teschl, M., 2004. .On the Emergence of Economic Identity. Revue de Philosophique Économique 9(1), 59-86.

Kirman A., Teschl, M., 2006. Searching for Identity in the Capability Space. Journal of Economic Methodology. 13(3), 299 - 325.

Mayo Clinic Staff, 2006. Spirituality and Stress Relief: Make the Connection, http://www.mayoclinic.com/health/stress-relief/SR00035

O’Donoghue, T., Rabin, M., 2001. Choice and Procrastination. Quarterly Journal of Economics 116:1, 121-60.

Parfit, D, 1971, Personal Identity. Philosophical Review 80(1) 3-27.

Schneiders, S., 1986. Theology and Spirituality: Strangers, Rivals, or Partners? Horizons 13, 253-74.

Sen, A., 1977. Rational Fools: A Critique of the Behavioral Foundations of Economic Theory. Economica 40(159), 241-59. 
Sen, A., 1985. Goals, Commitment and Identity. Journal of Law, Economics \& Organization 1(2), 341-55.

Sen, A., 1997. Maximization and the Act of Choice. Econometrica 65(4), 745-79.

Sen, A., 2002. Rationality and Freedom. Cambridge, MA: Belknap, Harvard University Press.

Teschl, Miriam, 2006. Personal Identity Decisions for Examining Change. Working Paper, Robinson College, University of Cambridge, UK. 